SINAI Journal of Applied Sciences 10 (3) $2021 \quad 551-558$

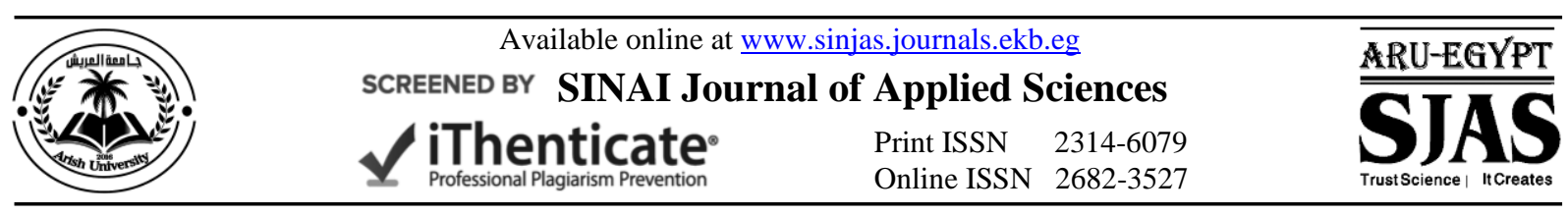

\title{
AN ECONOMIC STUDY OF OLIVE CROP IN NORTH SINAI GOVERNORATE
}

\author{
Walaa M. Newishi" ; Shomoo A. Mohamed and R.I.M. Radwan
}

Dept. Econ. and Rural Develop., Fac. Environ. Agric. Sci., Arish Univ., Egypt.

\begin{tabular}{l} 
ARTICLE INFO \\
\hline Article history: \\
Received: 04/09/2021 \\
Revised: 09/10/2021 \\
Accepted: $22 / 12 / 2021$ \\
Available online: $22 / 12 / 2021$ \\
\hline Keywords: \\
Measures of economic \\
efficiency, \\
possibilities of agricultural \\
expansion, \\
olive crop, \\
North Sinai Governorate \\
$\begin{array}{l}\text { Check for } \\
\text { updates }\end{array}$
\end{tabular}

\begin{abstract}
North Sinai Governorate is one of the promising governorates in olive production, as it ranks first in the list of crop composition of horticultural crops, with a relative importance of about $36.69 \%$ during 2018. North Sinai Governorate is also considered the olive oil exchange in Egypt in terms of quality and productivity, so it controls the prices of olives and its products with major producers, traders and brokers. The research relied on the use of financial evaluation criteria and economic efficiency measures in studying the efficiency of the performance of olive farms. In achieving its goals, it relied on two types of data, the first of which is the secondary data issued by the Ministry of Agriculture and Land Reclamation, the Economic Affairs Sector and the Directorate of Agriculture in North Sinai Governorate, and the second is the primary data that was obtained from a stratified random sample through a stratified random sample of 160 olive farms. Inside North Sinai Governorate during the 2019, 2020 average seasonal production. By studying the indicators of economic efficiency, the research showed that the general average of the return on costs, the return on the invested pound, the profit margin of the product, the relative profitability of the olive crop in North Sinai amounted to about $1.81,81.4 \%, 44.9 \%, 68.5 \%$, at the total of the sample farms, during the average seasonal production $(2019,2020)$. The general average of the economic efficiency of the olive crop in North Sinai amounted to about 1.06 pounds, meaning that each pound spent on fixed and variable production factors achieves an added value of about 1.06 pounds, at the level of the total sample farms, during the average seasonal production $(2019,2020)$.
\end{abstract}

\footnotetext{
الحفظ، بينمـا يستخدم نسبة محدودة منـه بلغت نحو 8) لإستخلاص زيت الزيتون (حجازي، 2012).

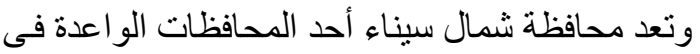

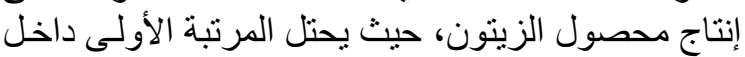

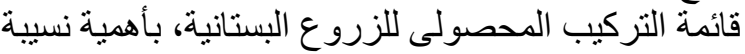

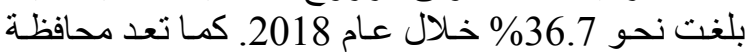

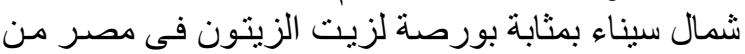

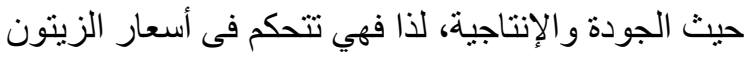
ومنتجاته لدى كبار المنتجين و التجار و الوسطاء. مشكلة البحث

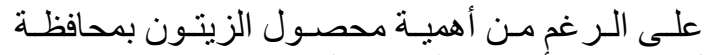

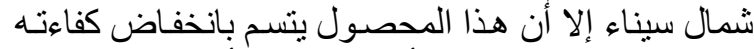

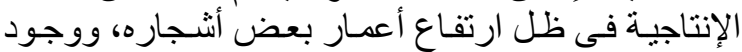

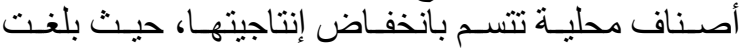

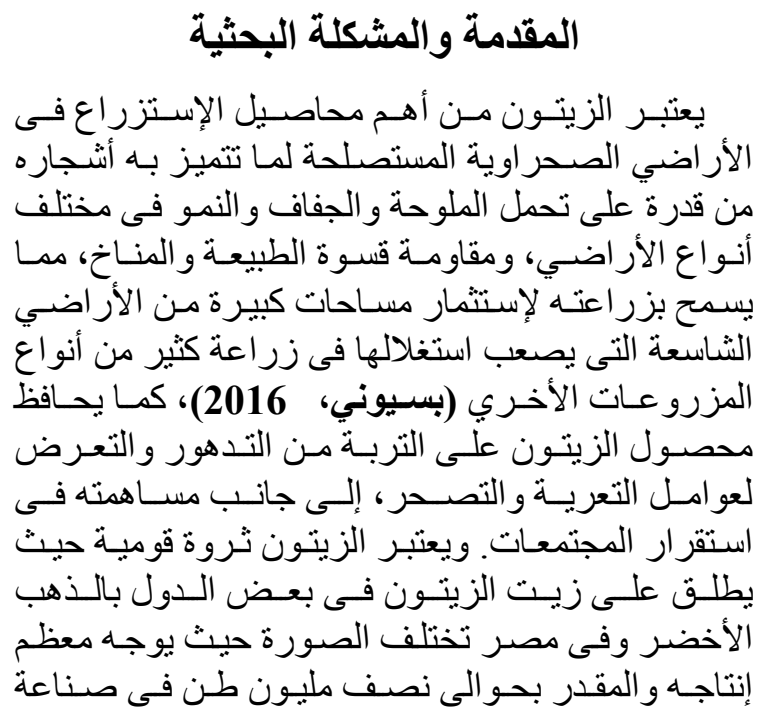

* Corresponding author: E-mail address: walaa_newishy@hotmail.com https://doi.org/10.21608/sinjas.2021.92406.1041

(C) 2021 SINAI Journal of Applied Sciences. Published by Fac. Environ. Agric. Sci., Arish Univ. All rights reserved. 
قو امهـا 160 مزر عـة لمحصـول الزيتـون داخل محافظــة شمال سيناء خلال منوسط موسمي إنتاج (2020،2019).

\section{النتائج والمناقشة}

\section{توصيف المتغيرات المرتبطة بعدد المزارع والحيازة

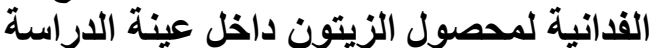

يوضتح جدول 1 نوصيف المتغير ات المرتبطـة بعدد

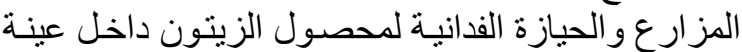

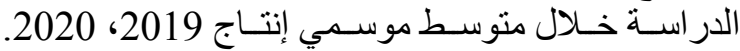

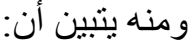

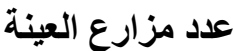

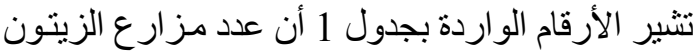

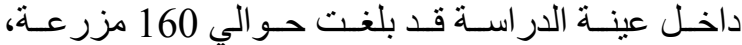

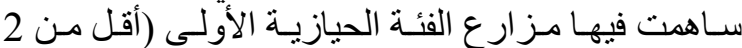

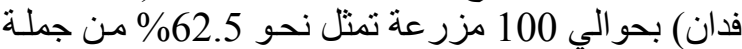

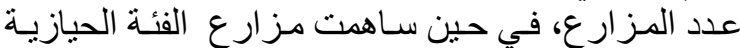

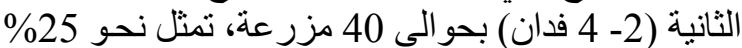

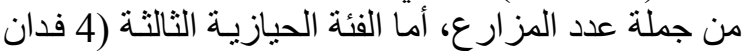

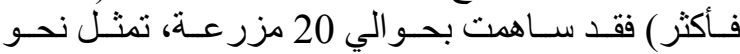
12.5\% من جملة عدد مز ارع العينة.

\section{الحيازة الفدانية}

أكدت الأرقام الواردة بجدول 1 أن متوسط نصسيب

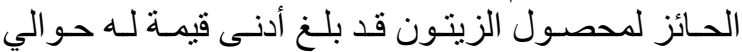

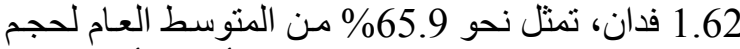

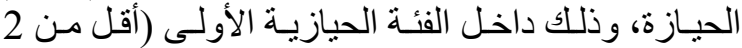

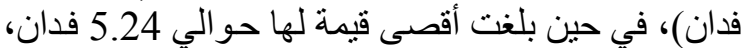

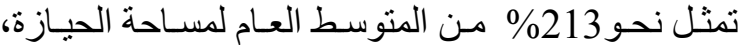

وذللك داخل الفئة الحيازية الثالثة (4 فدان فأكثر ).

هذا وقد بلـن المتوسط العـام لمسـاحة الحيـازة الفدانيـة

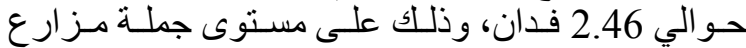
العينة، خلال منوسط موسمي إنتاج (2019،2020).

\section{توصـيف المتغيـرات المرتبطــة بالإنتاجيـة الفدانيـة لمحصول الزيتون داخل عينة الدراسة المالة}

يوضح جدول 2 توصيف المتغير ات المرتبطة بالإنتاجية الفدانية لمحصول الزيتون داخل عينـة الدر اسـة في شمال

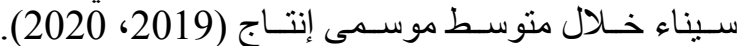

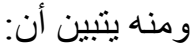

\section{عدد الأثجار المثمرة في الفدان}

تشير الأرقام بجدول 2 أن عدد الأشـجار في الفدان

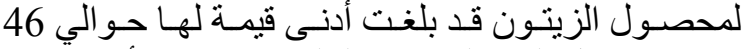

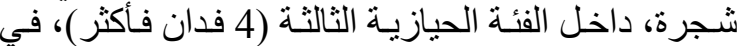

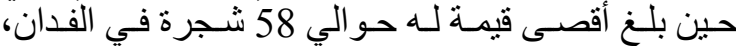
داخل الفئة الحيازية الأولى (أقل من 2 فدان).
إنتاجيـة الفـان في شـمال سيناء حـو الى 3.3 طـن، مقابـل

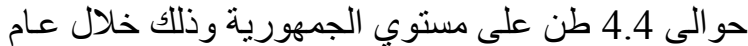

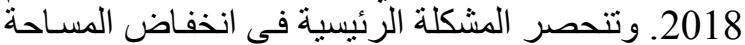

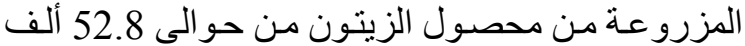

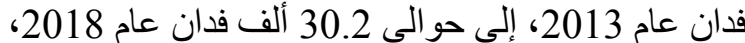

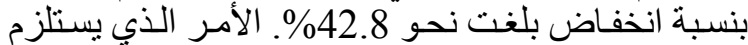
معاه در اسة اقتصاديات إنتاج هذا المحصول داخل مختلف الأفي الفي

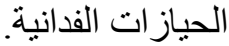

\section{أهداف البحث}

يستهدف البحث بصفة عامـة در اسـة الكفاءة الإنتاجيـة

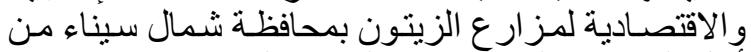

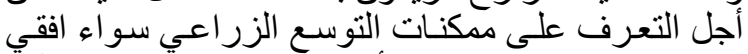

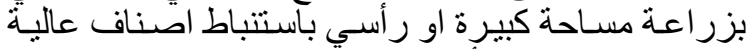

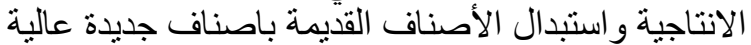

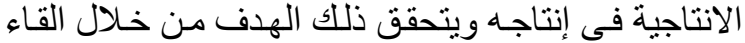
الضوء على الأهداف الفرعية التالية:

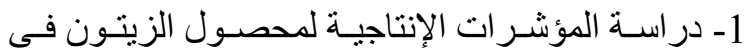

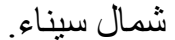

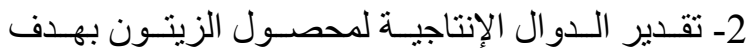

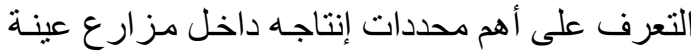

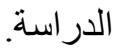
3- استعر اض مقاييس الكفاءة الإقتصادية لهذا المحصول

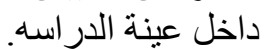

\section{مصادر البيانات والطريقة البحثية}

استخدم البحث أسلوب التحليل الوصفى في عرض التو التوب

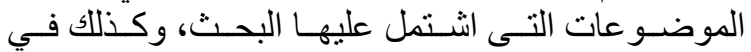

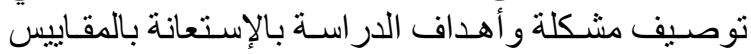

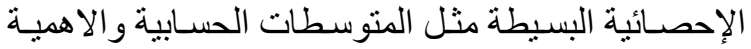

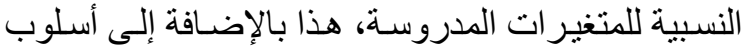

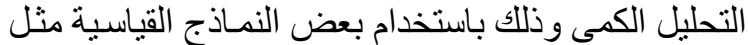

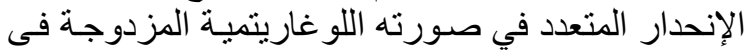

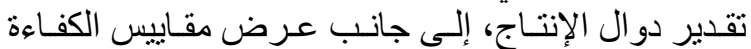

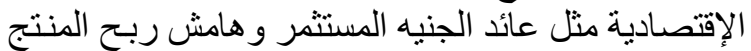

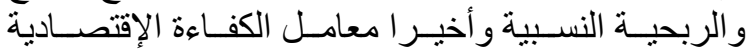

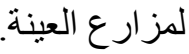

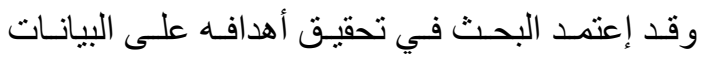

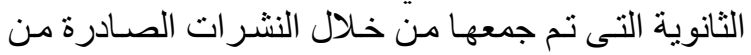

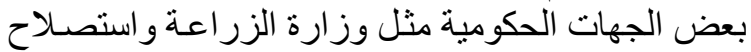

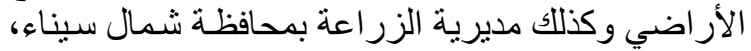

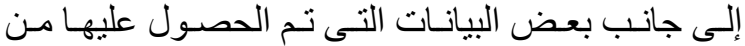
بعض الدر اسات و الأبحاث العلمية في مجال البحث. كما إعتمد البحث بصفة أساسية على البيانات البات الأولية

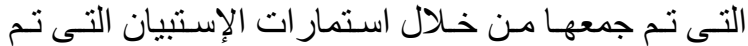

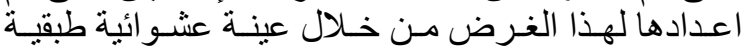


Newishi, et al. | SINAI Journal of Applied Sciences 10 (3) $2021551-558$

جدول 1. عدد مزارع الزيتون ومساحة الحيازة الفدانية داخل عينة الدراسة في محافظة شمال سيناء خلال متوسط موسمي إنتاج (2019، 2020)

\begin{tabular}{|c|c|c|c|c|}
\hline لجملة العينة العام & (4 الفئة الثاثلثة فأثثر) & الفئة الثانية & (أقل من الفئة الأولى فدان) & البيان \\
\hline 160 & 20 & 40 & 100 & عدد المزارع \\
\hline 100 & 12.5 & 25.0 & 62.5 & $\%$ \\
\hline 2.46 & 5.24 & 3.18 & 1.62 & متوسط الحيازة الفدانية (فدان) \\
\hline
\end{tabular}

جدول 2. الأهمية النسبية لعدد الأثجار المثمرة وإنتاجية الثجرة وإنتاجية الفدان لمحصول الزيتون داخل عينة الدراسة في شمال سيناء خلال متوسط موسمي إنتاج (2019،2020)

\begin{tabular}{|c|c|c|c|c|}
\hline لجملة العينة العام & 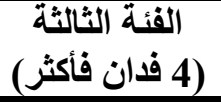 & الفئة الثانية & (أقل من الفئة الاولي فدان) & 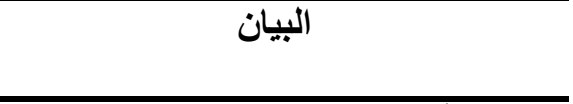 \\
\hline 56 & 46 & 55 & 58 & م. عدد الأشجار المثمرة في الفدان (شجرة) \\
\hline 75 & 80 & 75 & 75 & م. إنتاجية الشجرة (كجم/ سنة) \\
\hline 4210 & 3689 & 4121 & 4350 & م. إنتاجية القدان (كجم / سنة ) \\
\hline 100 & 87.6 & 97.9 & 103.3 & \% لإنتاجية الفدان من المتوسط العام \\
\hline
\end{tabular}

\section{نتـائج القياس الإحصـائى لأهم العوامـل المـؤثرة في

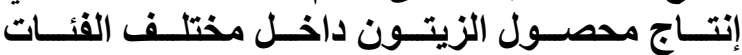 الحيازية بعينة الاراسة الزيتة}

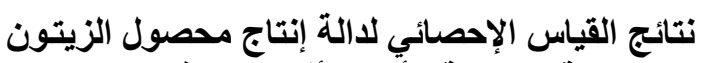
داخل الفئة الحيازية الأولى (أقل من 2 فدان)

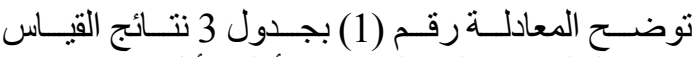

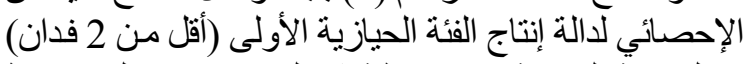

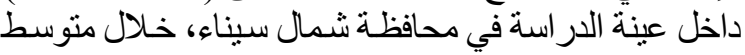

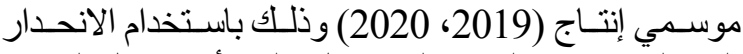

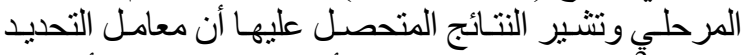

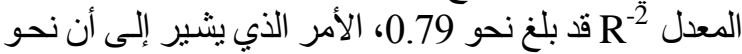

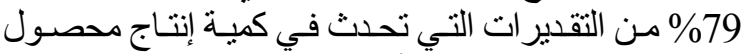

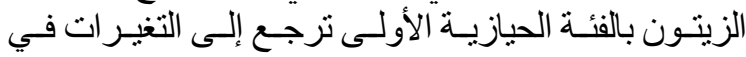
العو امل التي تتضمنها الدالة المذكورة.

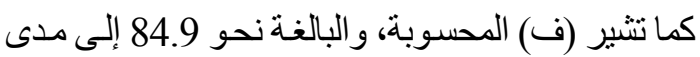

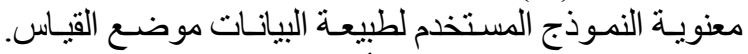

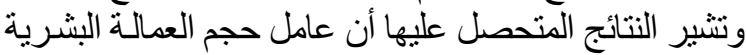

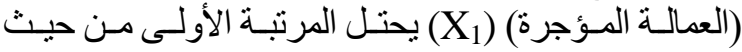

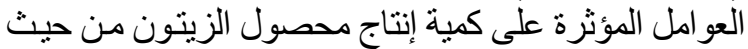

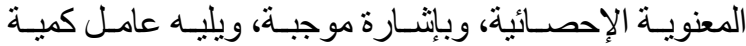

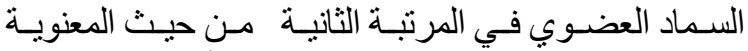

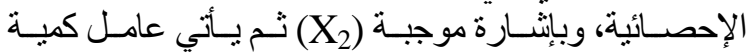

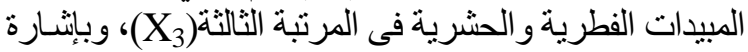

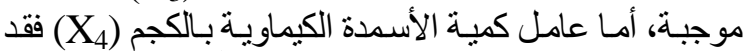

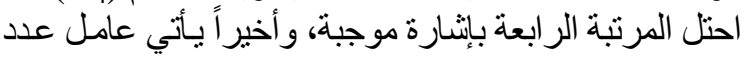

هذا وقد بلغ المتوسط العـام لعدد الأشجار في الفدان

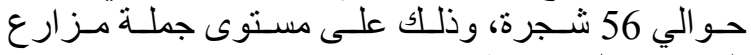
العينة، خلال منوسط إنتاج موسمي (2019، 2020).

إنتاجية الثجرة

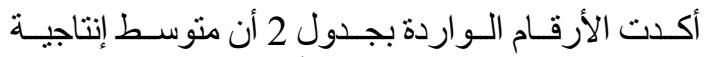

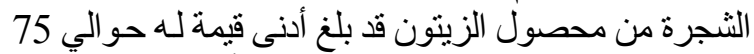

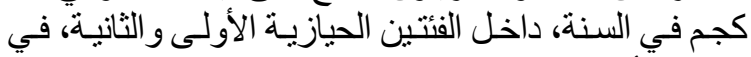

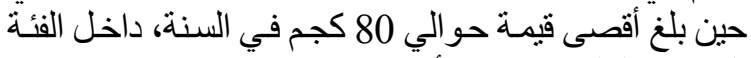
الحيازية الثالثة (4 فدان فأكثر) .

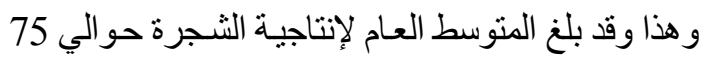

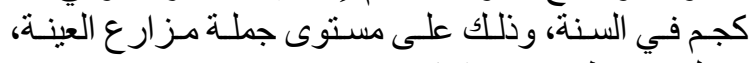
خلال متوسط موسمي إنتاج 2019، 2020.

إنتاجية الفدان

باستعر اض الأرقام الواردة بجدول 2 سـابق الإشـارة إليه

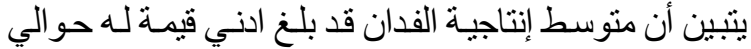

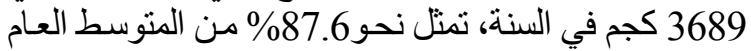

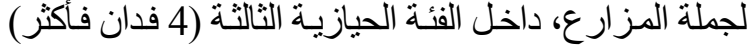

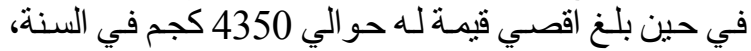
تمنتل نحو 103.3\% من المتوسط العام، داخل الفئة الحيازيـة فئة الأولى (2 فدان فأكثر).

هذا وقد بلغ المنتسط العام لإنتاجية الفدان من محصول

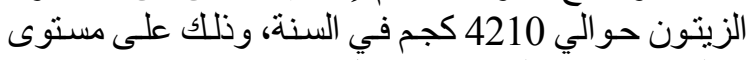

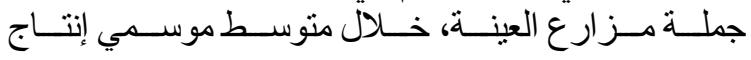
.(2020،2019) 


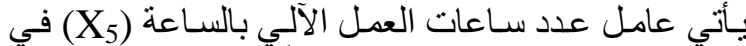
المرتبة الخامسة بإنثارة موجبة أيضاً.

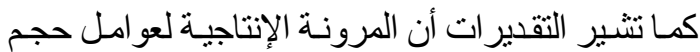

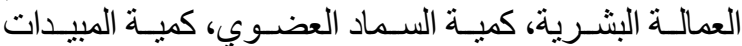

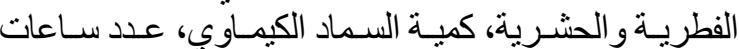

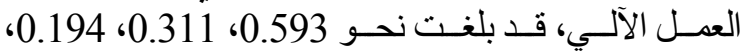

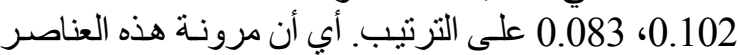

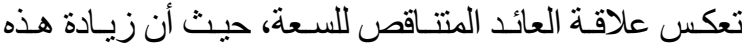

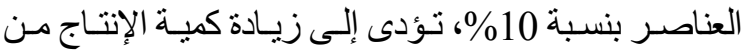

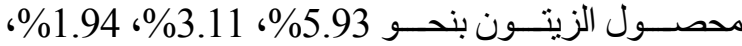

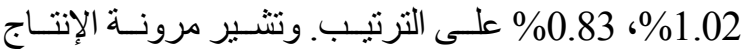

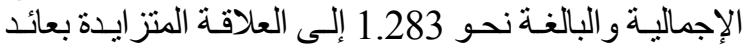

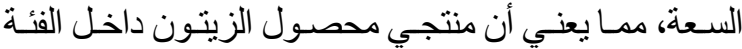

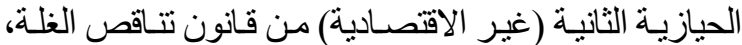
حيث أن كل زيادة تقدر بنحو 10\% في أغي الكميات المستخدمة

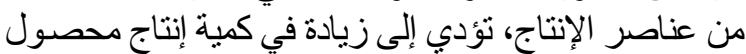

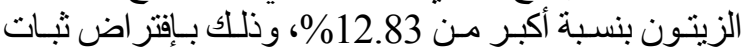

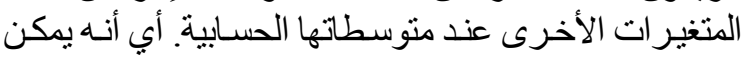

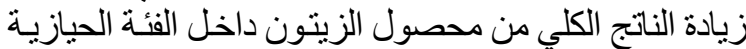

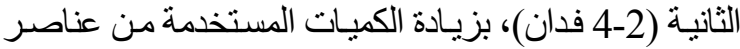

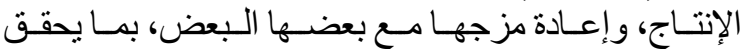
الاستخدام الأمثل لها، و هذا من شأنه زيادة أرباح المنتجين.

نتائج القياس الإحصائي لالة إنتاج محصول الزيتون داخل الفئة الحيازية الثالثة (4 فدان فأكثر)

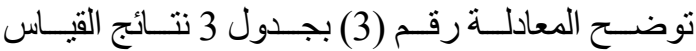

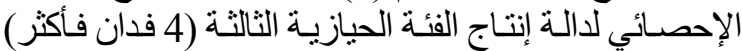

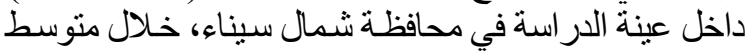

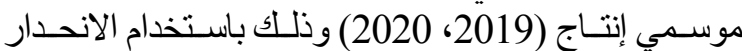

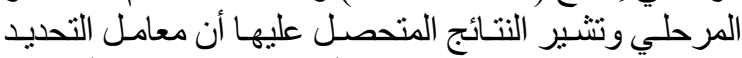
المعدل R-2 قد بلغ نحو 0.88 الأمر الذي يشير إلى إنى أن نحو

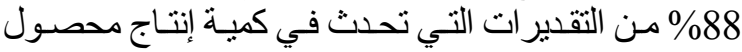

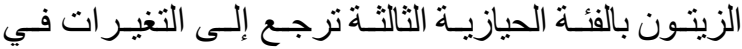
العوامل التي تتضمنها الدالة المذكورة.

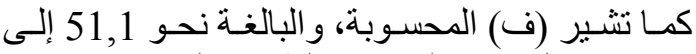

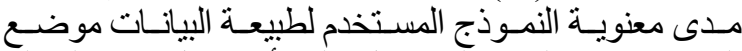

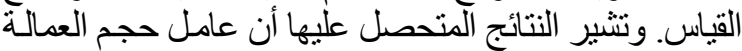

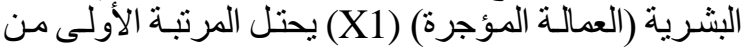

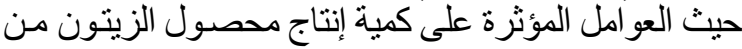

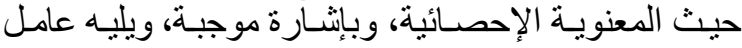

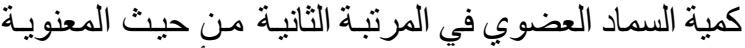

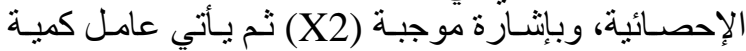

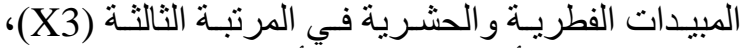

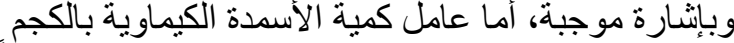

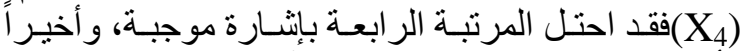

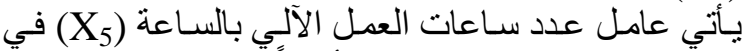
المرتبة الخامسة بإثـارة موجبة أيضاً.

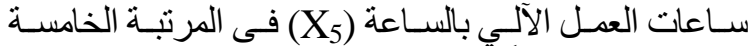
بإنتارة موجبة أيضاً.

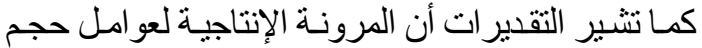

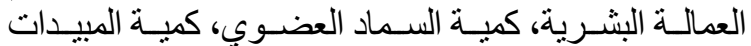

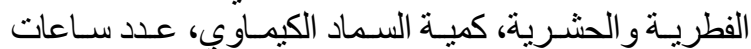

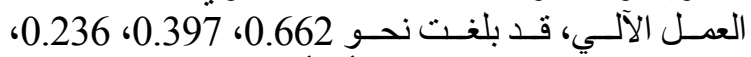

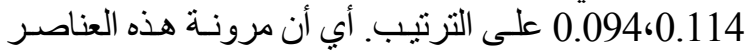

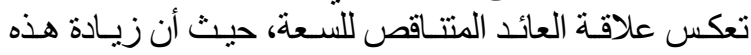

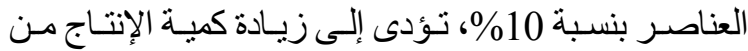

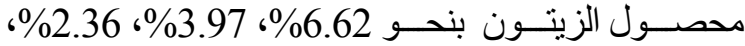

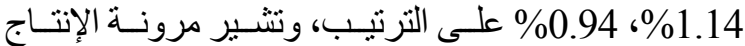

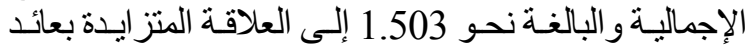

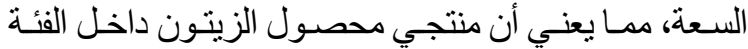

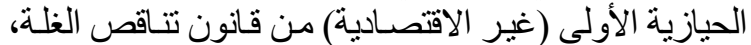

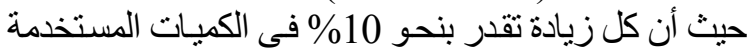

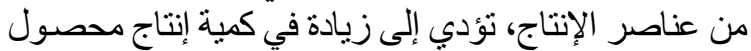

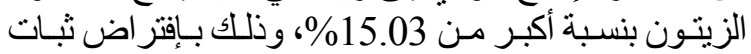
المتغير ات الأخرى عند متوسطاتها الحسـابية. أبي أنسه يمكن

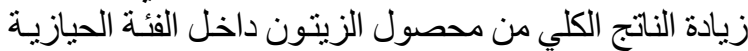

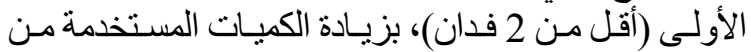

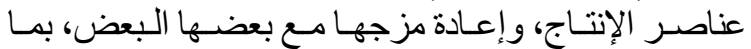
يحقق الاستخدام الأمثنل لهـا، وهـذا مـن شـأنها زيـادة أربـاح

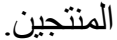

نتائج القياس الإحصائي لالة إنتاج محصول الزيتون داخل الفئة الحيازية الثانية (من2-4 فدان)

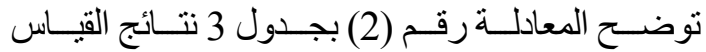

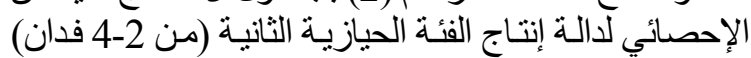

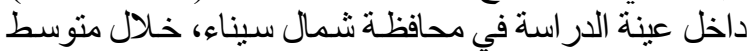

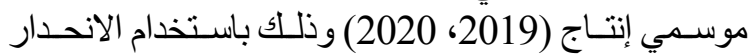
المرحلي وتثير النتائج المتحصل عليهـا أن معامل التحديد

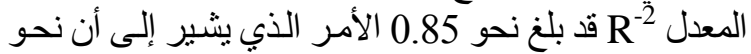

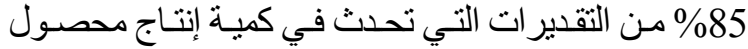

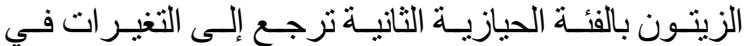
العو امل التي تتضندنها الدالة المذكورة.

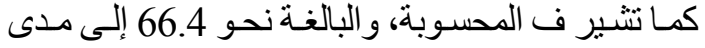

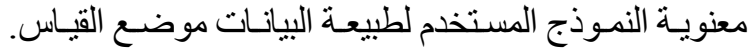

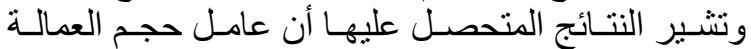

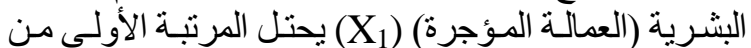

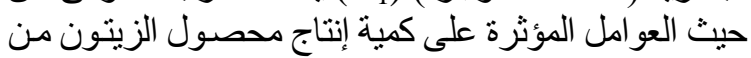

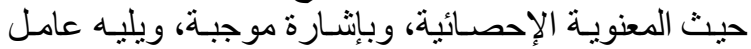

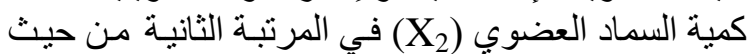

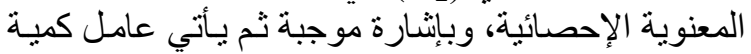

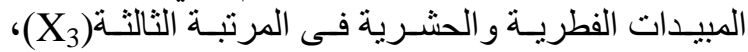

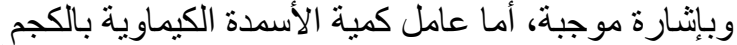

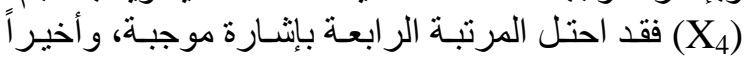


جدول 3. نتائج القياس الإحصائي لعلاقة إنتاج محصول الزيتون بأهم عناصره داخل مختلف الفئات الحيازية بعينة الدراسة في محافظة شمال سيناء خلال متوسط عامي 2019-

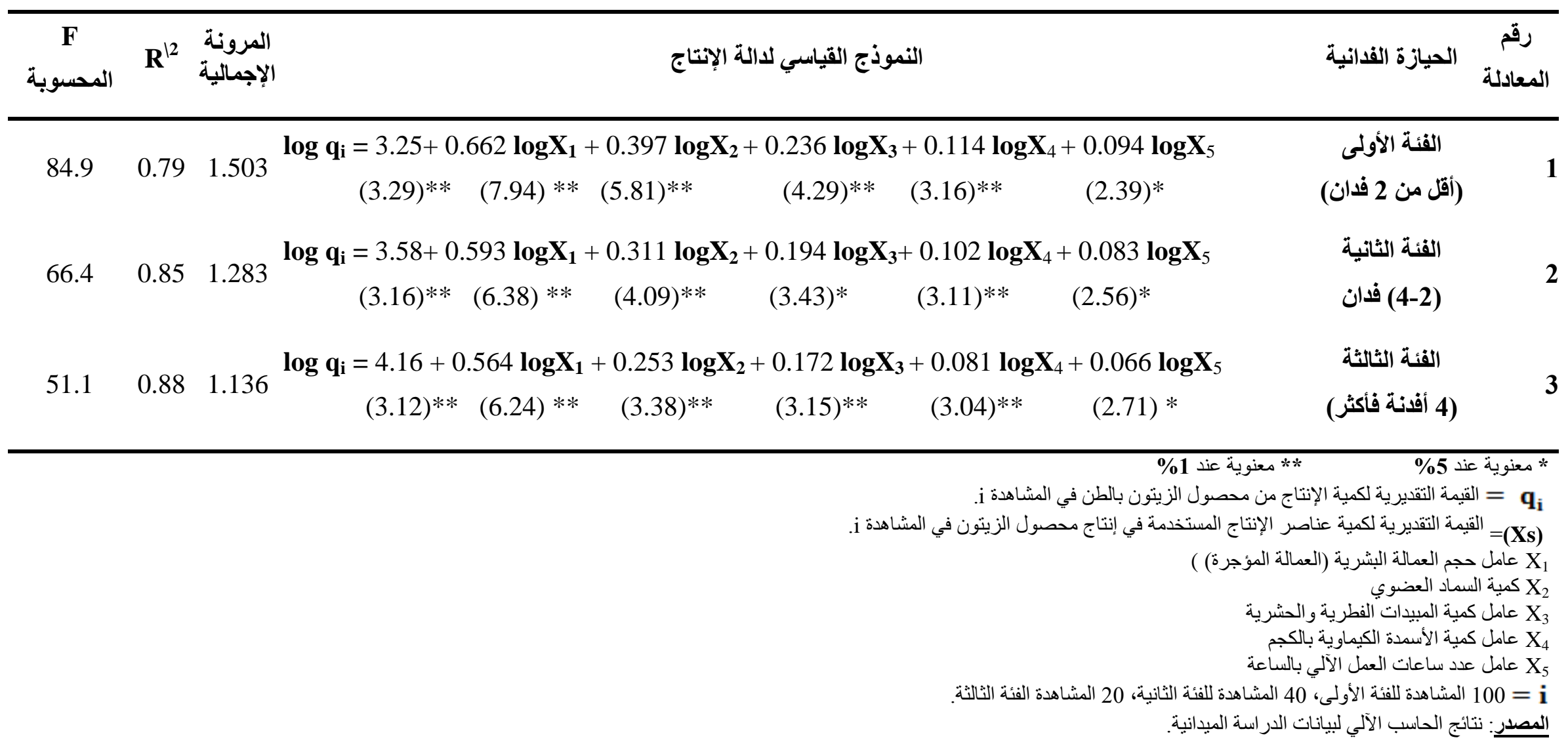




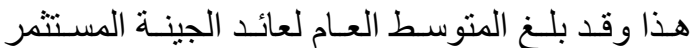

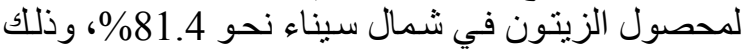
على مستوى جملة مزارع العينة فئة، خلال متوسط موسمي وني إنتاج (2019، 2020).

\section{هامش ربح المنتج}

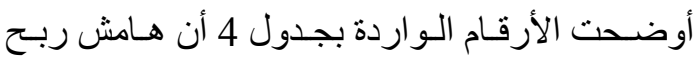

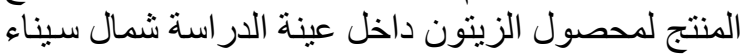

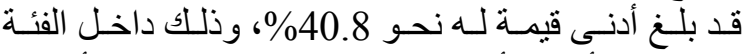

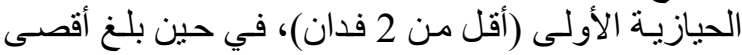
قيمة له نحو 60.6\%، داخل الفئة الحيازية الثالثة (4 فدان

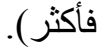

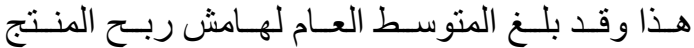

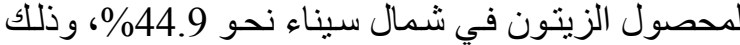

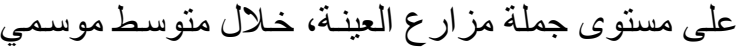
إنتاج (2019، 2020).

\section{الربحية النسبية}

تشـير الأرقـام الـواردة بجدول 4 أن الربحيـة النسـبية لمحصول الزيتون داخل عينة الدر اسة في محافظة شمال الخمال

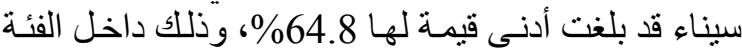

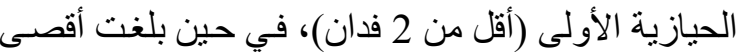

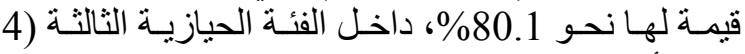

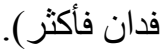

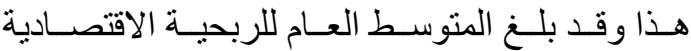
لمحصول الزيتون في شمال سيناء نحو

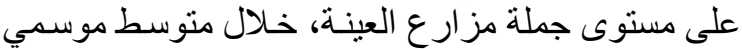
إنتاج (2019، 2020).

\section{الكفاعة الاقتصادية}

باستعر اض الأرقام الواردة بجدول 4 سـابق الإشـارة

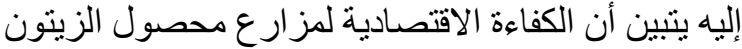

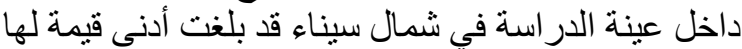
حوالي 0.94 جنيه داخل الفئة الحيازية الأولى (أقل من 2

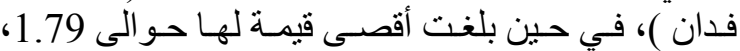
داخل الفئة الحيازية الثالثة (4 فدان فأكثر ).

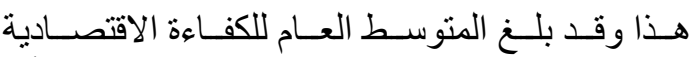

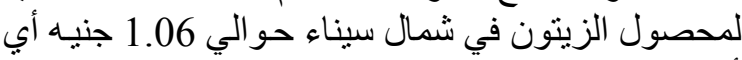

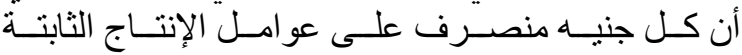

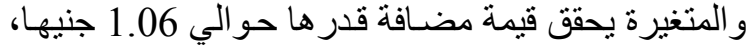

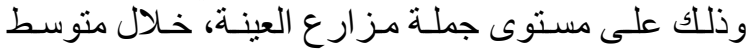
موسمي إنتاج (2019، 2020).

ويوصسى البحـث بضـرورة التوسـع الأفقى في إنتـاج

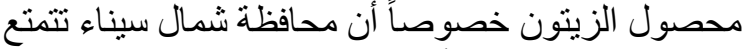

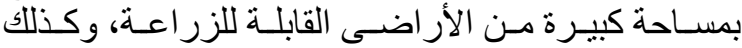

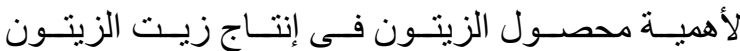

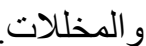

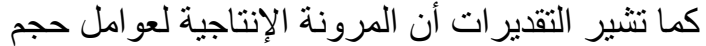

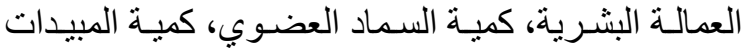

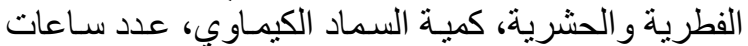

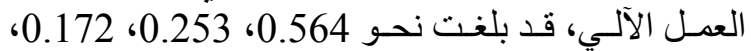

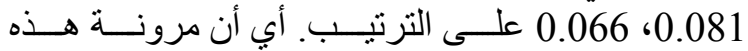

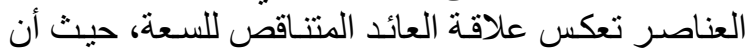

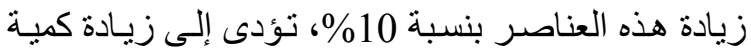

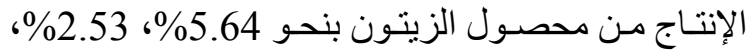

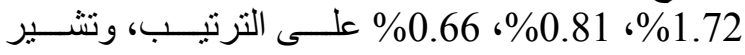

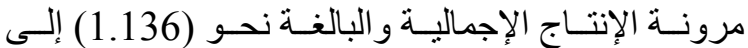

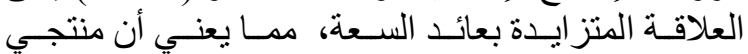

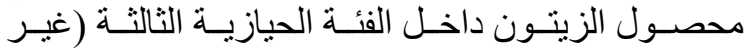

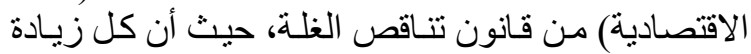

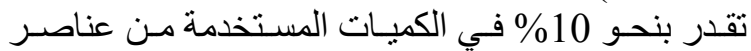

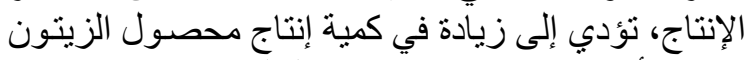

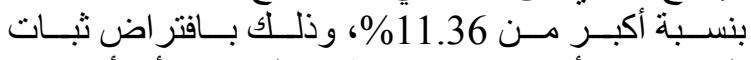
المتغير ات الأخرى عند منوسطاتها الحسابية. أب أنه يمكن

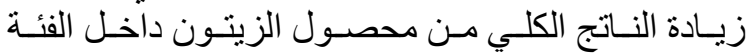

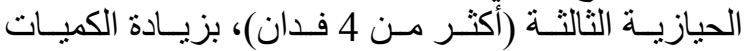

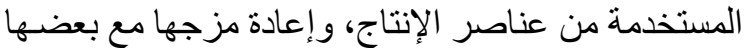
البعض، بمـا يحقق الاستخذام الأمثل لها، وهذا، وهذا من شـأنه

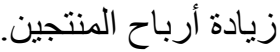

مقاييس الكفاءة الاقتصادية لمحصول الزيتون داخل

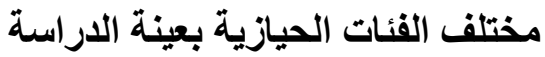

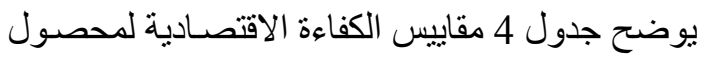

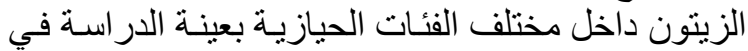

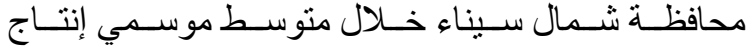
(2019، 2020). ومنه ينتين:

\section{نسبة العائد للتكاليف}

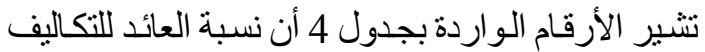

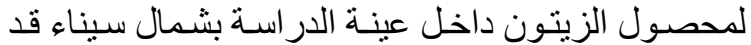
بلغت أدنى قيمة لها نحو 1.69 1.6و، وذللك داخل الفئة الحيازيـة

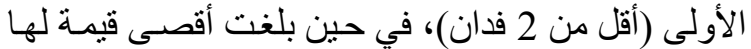
نحو 2.54، داخل الفئة الحيازية الثالثة (4 فدان فأكثر ).

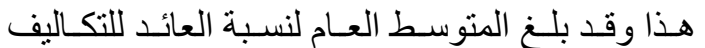

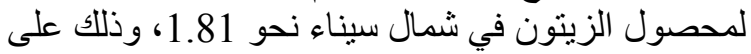
مستوى جملة مز ارع العينة، خلان فئل متوسط موسمي إنتاج

.2020، 2019)

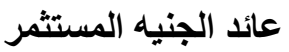

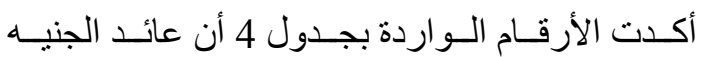

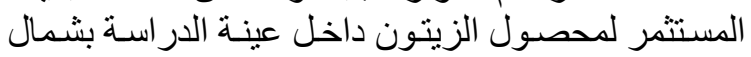

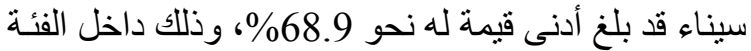

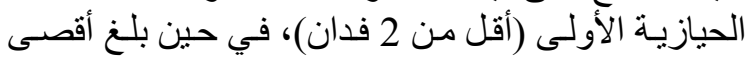

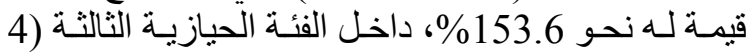

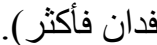


Newishi, et al. | SINAI Journal of Applied Sciences 10 (3) $2021551-558$

جدول 4. مقاييس الكفاعة الاقتصادية لمحصول الزيتون داخل مختلف الفئات الحيازية بعينة الدراسة في محافظة شمال سيناء خلال متوسط موسمي إنتاج (2019،

\begin{tabular}{|c|c|c|c|c|}
\hline المتوسط العام لجملة & 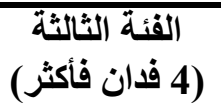 & (الفئة الثانية & (أقلّ من الفئة الأولى 2 فذان) & مقاييس الكفاءة الاقتصادية \\
\hline 1.81 & 2.54 & 1.94 & 1.69 & نسبة العائد للتكاليف (1) \\
\hline 81.4 & 153.6 & 94.2 & 68.9 & عائد الجنيه المستثمر(2) \\
\hline 44.9 & 60.6 & 48.5 & 40.8 & هامش ربح المنتج (3) \\
\hline 68.5 & 80.1 & 71.5 & 64.8 & الربحية النسبية (4) \\
\hline 1.06 & 1.79 & 1.19 & 0.94 & الكفاعة الاقتصادية (5) \\
\hline ل العائد/ جملة الاير ادات. & $\overline{\Delta=(3)}$ & 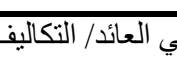 & & (1) = الاير اردات / التكاليف الكلية \\
\hline \multicolumn{3}{|c|}{ (5) = القيمة المضافة / تكاليف الإنتاج. } & \multicolumn{2}{|c|}{ (4) = صافي العائد/ العائد فوق التكاليف المتغيرة . } \\
\hline
\end{tabular}

حجازي، سعيد صادق (2012). سيناء وآفاق جديدة لزراعة الزيتون، المجلة الزر اعية، 54 : 629.

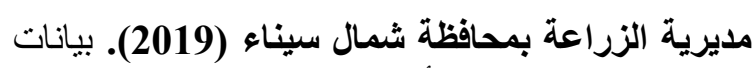
ثانوية غير منشورة، أعداد متفرقة.

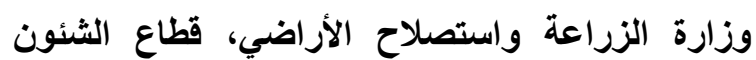
الاقتصادية، نثرة المسلحة المحصولية (أعداد متفرقة).

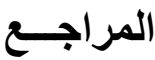

بسيوني، شاكر جمعة أحمد (2016). دراسة اقتصنادية

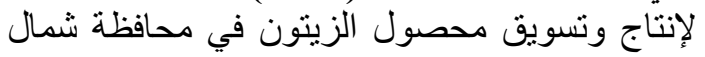

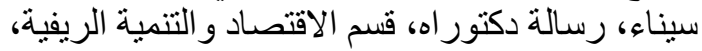
كلية العلوم الزراعية البيئية، جامعة العريش. 


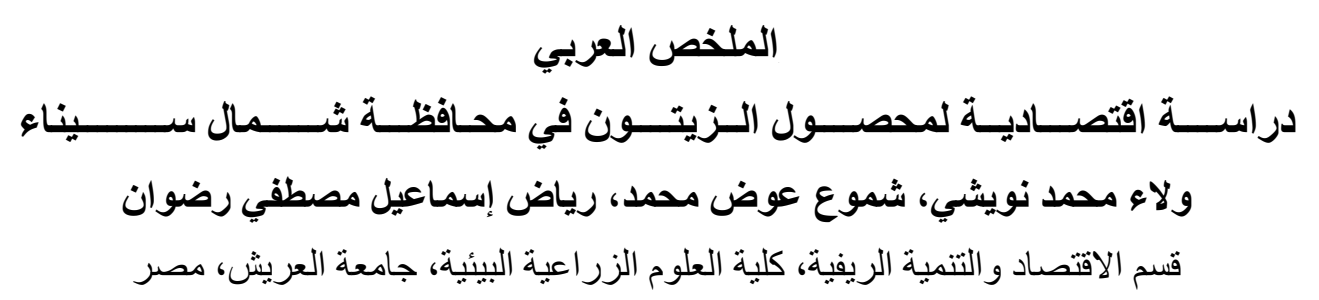

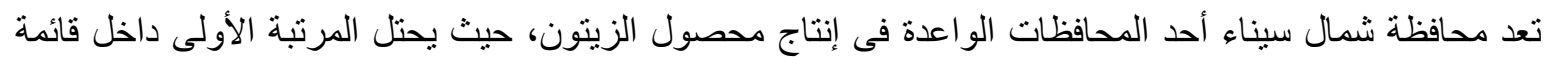

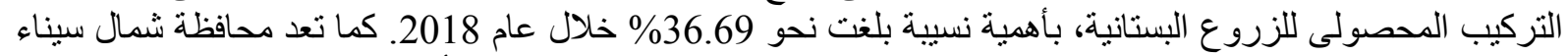

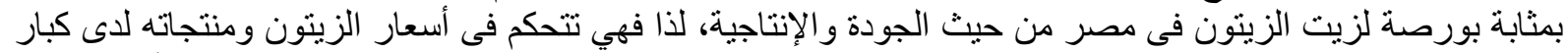

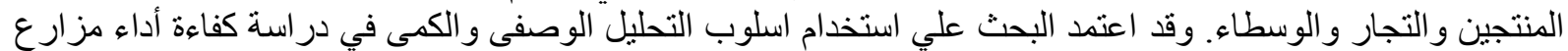

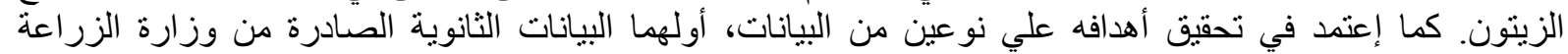

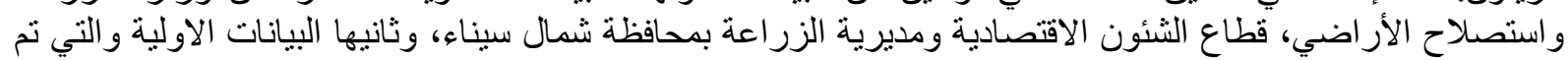

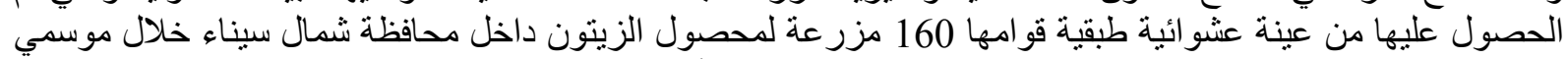

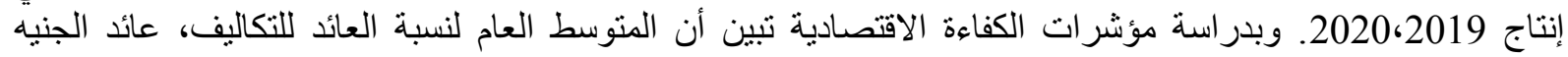

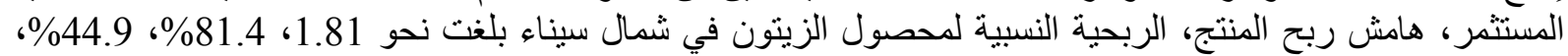

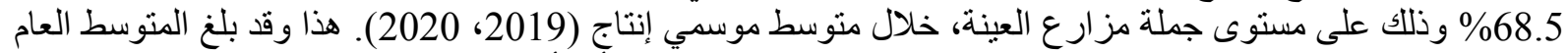

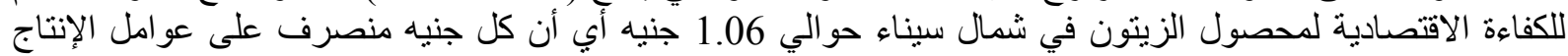

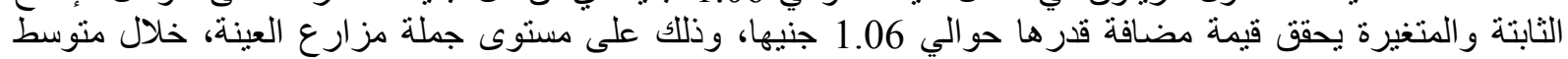
موسمي إنتاج (2019، 2020).

الكلمات الاسترشادية: مقاييس الكفاءة الاقتصادية، ممكنات التوسع الزراعي، محصول الزيتون، محافظة شمال سيناء. 